\title{
Does relatedness matter? Phylogenetic density-dependent survival of seedlings in a tropical forest
}

\author{
Edwin Lebrija-Trejos, ${ }^{1,2,4}$ S. Joseph Wright, ${ }^{1}$ Andrés Hernández, ${ }^{1}$ and Peter B. Reich ${ }^{2,3}$ \\ ${ }^{1}$ Smithsonian Tropical Research Institute, Apartado 0843-03092, Balboa Ancón, Panama \\ ${ }^{2}$ Department of Forest Resources, University of Minnesota, 1530 Cleveland Avenue North, St. Paul, Minnesota 55108 USA \\ ${ }^{3}$ Hawkesbury Institute for the Environment, University of Western Sydney, Richmond 2753 Australia
}

\begin{abstract}
A complex set of interactions among neighbors influences plant performance and community structure. Understanding their joint operation requires extensive information on species characteristics and individual performance. We evaluated first-year survival of 35719 tropical forest seedlings of 222 species and 15 annual cohorts relative to the density of conspecific and heterospecific neighbors and the phylogenetic similarity of heterospecific neighbors. Neighbors were from two size classes, and size asymmetric interactions provided insight into likely mechanisms. Large heterospecific and conspecific neighbors reduced seedling survival equally, suggesting resource competition rather than host-specific enemies as a mechanism. In contrast, much stronger negative conspecific effects were associated with seedling neighbors capable of limited resource uptake, suggesting shared pests rather than competition as the mechanism. Survival improved, however, near phylogenetically similar heterospecific neighbors, suggesting habitat associations shared among closely related species affect spatial patterns of performance. Improved performance near phylogenetically similar neighbors is an emerging pattern in the handful of similar studies.
\end{abstract}

Key words: average relative phylodiversity (APd'); conspecific; density dependence; functional traits; heterospecific; neighborhood; Panama; phylogenetic distance; phylogenetic signal; relative nearest taxon phylodiversity (NTPd'); seedling survival; tropical forest.

\section{INTRODUCTION}

Plant diversity of wet tropical forests challenges species coexistence theories (Wilson et al. 2012). Species coexistence requires stabilizing mechanisms that increase negative conspecific interactions relative to negative heterospecific interactions (Chesson 2000). The challenge is to identify mechanisms that increase negative conspecific interactions among hundreds of plant species, most of which are extremely rare. The hundreds of syntopic plant species in tropical forests support many thousands of syntopic species of insects, fungi, and bacteria (Arnold et al. 2000, Basset et al. 2012, Baldeck et al. 2013). Even though many mutually compatible mechanisms probably contribute to plant species coexistence in tropical forests, the search for stabilizing mechanisms has focused on negative frequency or density-dependent interactions mediated by those microbes and insects acting as pathogens, seed predators, and herbivores (reviewed by Wright 2002, Terborgh 2012).

The search for evidence for stabilizing mechanisms has focused on negative density-dependent (NDD) recruitment, growth, and/or survival (collectively performance) among conspecifics (Wright 2002). Plant

Manuscript received 3 April 2013; revised 23 August 2013; accepted 28 August 2013. Corresponding Editor: B. A. Roy.

${ }^{4}$ E-mail: elebrija@gmail.com performance integrates local abiotic conditions; the actions of microbes, insects, and other animals; and negative and positive interactions with neighboring plants. Negative interactions with neighboring plants might be caused by shared pests (pathogens, herbivores) and/or by competition for limiting resources. Positive interactions with neighbors might be caused by shared mutualists (mycorrhizae), by facilitation (nurse plants), and/or by shared responses to abiotic conditions. Net evidence for unidentified stabilizing mechanisms is realized when spatial variation in performance and conspecific density are negatively related (Wright 2002).

Heterospecifics comprise most neighbors in speciesrich tropical forests. Interactions with heterospecifics and conspecifics are fundamentally similar (resources are consumed and microbes and animals are shared), but the balance between positive and negative and direct and indirect interactions is complicated by differences among heterospecific species. Closely related plant species tend to share the same limiting resources and the same pest species for pests ranging from viruses to herbivorous snails (Vamosi et al. 2009, Gilbert et al. 2012). The same variety of pests causes NDD among conspecifics (Janzen 1970, Augspurger and Kelly 1984, Alvarez-Loayza and Terborgh 2011). For these reasons, NDD performance might extend to include the density of closely related heterospecifics (Webb et al. 2006, Bagchi et al. 2010, Liu et al. 2012, Paine et al. 2012). However, closely related plant species also tend to 
respond similarly to abiotic variation and to share species of mutualists (Herre et al. 2005, Vamosi et al. 2009, Kress et al. 2009, Burns and Strauss 2011). Thus, there seems to be no a priori reason for negative effects of closely related heterospecific neighbors to overwhelm positive effects. We can only conclude that plant performance might vary with phylogenetic divergence times of heterospecific neighbors, as well as with the size and density of conspecific and heterospecific neighbors.

Plant diversity in tropical forests also challenges analytical methods. Many species are at such low densities that it is infeasible to collect enough data for meaningful species-level analyses. Bayesian and generalized linear mixed-model (GLMM) approaches have recently overcome this limitation, and it is now possible to include rare species while properly accounting for sample sizes (Rüger et al. 2009, Chen et al. 2010, Comita et al. 2010). In this study, we used GLMMs to analyze first-year survival of $>35700$ seedlings from 15 annual cohorts relative to neighborhood composition in the moist tropical forest of Barro Colorado Island (BCI), Panama. We divided neighbors between conspecifics and heterospecifics and between small juveniles and larger individuals because differences in their effects can help discriminate among possible mechanisms of interaction (Terborgh 2012). We further assessed whether the effects of heterospecific neighbors vary with phylogenetic relatedness to the focal seedling. To this end, we used a highly resolved phylogeny that includes $98 \%$ of all neighboring tree, shrub, and liana species (Kress et al. 2009; D. L. Erickson et al., unpublished manuscript). We used standard summary metrics of phylogenetic relatedness calculated over all neighbors (Webb et al. 2006) and also separated heterospecifics into groups that correspond to the divergence time of major taxonomic ranks. This permited us to evaluate effects of phylogenetic relatedness at scales that differ with respect to ecological similarity and the strength of species interactions (Vamosi et al. 2009). To evaluate the link between relatedness and ecological similarity, we tested for phylogenetic signal in 19 functional traits related to resource capture, defense, and stress tolerance.

We predicted both conspecific and heterospecific NDD, with the former being stronger than the latter. If resource competition contributes strongly to NDD, we predicted stronger effects of large individuals than seedlings because competition is size asymmetric in closed-canopy forests (Coomes et al. 2011). We expected significant trait conservatism, and therefore, a significant effect of phylogenetic relatedness among heterospecifics. If positive interactions (shared mutualists and habitat associations) are more important, we predicted survival would increase among closely related neighbors. Conversely, if negative interactions (shared pests and resource competition) are more important, we predicted survival would increase among distantly related neighbors.

\section{Methods}

Site and censuses

BCI $\left(9.15^{\circ} \mathrm{N}, 79.85^{\circ} \mathrm{W}\right)$ supports tropical moist forest in the Holdridge Life Zone System. Annual rainfall averages $2600 \mathrm{~mm}$, with just $10 \%$ falling during a fourmonth dry season. Temperature averages $26^{\circ} \mathrm{C}$ for 11 months and $27^{\circ} \mathrm{C}$ in April. In a 50-ha, old-growth forest dynamics plot (FDP), all free-standing woody plants $>1$ $\mathrm{cm}$ diameter at breast height ( $\mathrm{dbh}$ ) were identified to species, mapped to the nearest $0.5 \mathrm{~m}$, and measured for dbh in 1982, 1985, and each five years thereafter (see Condit 1998 for methods). In $8001-\mathrm{m}^{2}$ seedling plots, all woody seedlings and vines were identified to species and measured for height and leaf number each dry season since 1994 (see Wright et al. 2005 for methods). The 800 seedling plots are located at 250 stations in the FDP. The first 200 stations were established in 1994 from 4 to $10 \mathrm{~m}$ from pre-existing trails in a stratified random manner. The remaining 50 stations were established between 2002 and 2004 in naturally occurring tree fall gaps (Puerta-Piñero et al. 2013). Each station includes a central seed trap with seedling plots $2 \mathrm{~m}$ from three and four sides of the first 200 and remaining 50 traps, respectively. There is no lower size threshold (all recruits are included). Germination is concentrated in the first months of the wet season and falls virtually to zero throughout the dry season on BCI (Garwood 1983). The dry-season census thus avoids germination during the census period and excludes ephemeral germinants that fail to establish during their first wet season.

\section{Phylogeny}

Divergence times between neighbors and focal seedlings equaled the sum of branch lengths for a DNA barcode phylogeny of 465 species of shrubs, trees, and climbers of BCI (Kress et al. 2009; D. L. Erickson et al., unpublished manuscript). Nodes were dated using the time constraints of Magallón and Castillo (2009) and PATHd8 (Britton et al. 2007), with the gymnosperm/ angiosperm node fixed at 300 million years ago (Mya). The barcode phylogeny lacked 16 and 91 of the species identified in the 50-ha plot and seedling censuses, respectively ( 94 species total). We attached 56 and 26 of these species to the barcode phylogeny as polytomies at the genus and family levels, respectively, using PHYLOMATIC (Webb and Donoghue 2005). We attached two more species as sister genera at half the sister taxon branch length using the R package APE and phylogenies published at TreeBASE (available online). ${ }^{5}$ The 10 species absent from the final phylogeny were rare and represented $<0.1 \%$ of censused plants.

\section{Analyses}

We evaluated phylogenetic conservatism for 19 functional traits related to resource capture, defense,

\footnotetext{
${ }^{5}$ www.treebase.org
} 
TABLE 1. Range, mean, and standard deviation of fixed-effects covariates.

\begin{tabular}{|c|c|c|c|c|c|c|c|c|}
\hline \multirow[b]{2}{*}{ Factor } & \multicolumn{3}{|c|}{ Seedling neighbors (individuals $/ \mathrm{m}^{2}$ ) } & \multicolumn{3}{|c|}{ Neighbors $\geq 1 \mathrm{~cm} \mathrm{dbh \dagger}$} & \multirow[b]{2}{*}{ Species } & \multirow[b]{2}{*}{ Seedlings } \\
\hline & Range & Mean & SD & Range & Mean & $\mathrm{SD}$ & & \\
\hline Conspecific & $0-132$ & 11.55 & 20.90 & $0-5$ & 0.381 & 0.656 & & \\
\hline Heterospecific & $1-155$ & 18.56 & 14.84 & $0-13$ & 4.828 & 2.027 & & \\
\hline \multicolumn{9}{|c|}{$\begin{array}{l}\text { Indices of divergence time of } \\
\text { heterospecific neighbors }\end{array}$} \\
\hline APd' & -4.42 to 3.44 & -0.021 & 1.055 & -4.83 to 3.71 & -0.069 & 1.107 & & \\
\hline NTPd' & -4.54 to 2.49 & -0.015 & 0.974 & -4.67 to 2.32 & -0.075 & 1.090 & & \\
\hline $\mathrm{D}<15$ Мya & $0-1$ & 0.008 & 0.040 & $0-1$ & 0.013 & 0.064 & 148 & 23407 \\
\hline D 15-50 Муа & $0-1$ & 0.009 & 0.045 & $0-1$ & 0.015 & 0.065 & 172 & 20500 \\
\hline D $50-85$ Мyа & $0-1$ & 0.169 & 0.211 & $0-1$ & 0.141 & 0.209 & 213 & 34942 \\
\hline D 85-120 Муа & $0-1$ & 0.654 & 0.315 & $0-1$ & 0.637 & 0.323 & 195 & 32355 \\
\hline $\mathrm{D}>120 \mathrm{Mya}$ & $0-1$ & 0.159 & 0.291 & $0-1$ & 0.195 & 0.292 & 222 & 35719 \\
\hline
\end{tabular}

Notes: Each model included the density of conspecific and heterospecific neighbors and one of three possible indices of heterospecific divergence time. The three indices are average relative phylodiversity (APd'), relative nearest taxon phylodiversity (NTPd'), and proportions of heterospecific neighbors that diverged (D) $<15$ million years ago (Mya), 15-50 Mya, 50-80 Mya, 80$120 \mathrm{Mya}$, and >120 Mya. The final two columns present the number of focal species and seedlings that could potentially have neighbors in each relatedness category. Webb et al. (2006) define APd' and NTPd'. The final two columns were calculated using the DNA barcode phylogeny of 465 species of shrubs, trees, and lianas of Barro Colorado Island (BCI), Panama, with 84 species added as genus- or family-level polytomies (see Methods for details).

$\uparrow$ Number of individuals within one crown radius.

and stress tolerance (see Wright et al. 2010 for traits methods). We used a randomization test and the ultrametric bar code phylogeny to evaluate the significance of phylogenetic signal. The randomization shuffled traits across the tips of the phylogeny to create a null distribution for the variance of phylogenetically independent contrasts (PICs), and thus, makes no evolutionary model assumption (Kembel et al. 2010). Sixteen leaf traits were analyzed separately for leaves from shaded and sunny conditions.

We analyzed survival of recruits over their first full year. We excluded seedlings encountered in the first census of a plot (1994 for the first 200 stations and 2002, 2003, or 2004 for the remaining 50 stations) because their ages were unknown. The final census was in 2010 for all stations. Thus, the final cohort of recruits was from 2009. We analyzed binary survival data (alive/ dead) with binomial error distributions using GLMMs and the lme4 package in R 2.15.1 (R Core Development Team 2012). Random effects were species, year, station, and plot nested within station. These random effects account for interspecific, temporal, and spatial variation. For the species random effect, we also included coefficients with each fixed effect. These coefficients or slopes account for interspecific variation in response to the fixed effects.

The fixed-effects capture neighborhood composition and include conspecific density, heterospecific density, and an index of relatedness of heterospecific neighbors (Table 1). We calculated the fixed effects separately for seedlings and larger plants. Seedling neighbors included all woody plants and vines $<1 \mathrm{~cm}$ dbh in the $1-\mathrm{m}^{2}$ plot of the focal seedling. Larger neighbors included all freestanding woody plants $\geq 1 \mathrm{~cm}$ dbh within one crown radius of the $1-\mathrm{m}^{2}$ plot. Crown radii were estimated from allometric relationships between $\mathrm{dbh}$ and crown diameter of BCI trees (Muller-Landau et al. 2006). We interpolated densities of larger plants for years between the five-year FDP censuses (Comita et al. 2010). Thus, $t$ $(0 \leq t \leq 4)$ years after the FDP census in year $y$ the density of species $j$ was estimated as $D_{j(y+t)}=D_{j y}+0.2 \times$ $t \times\left(D_{j(y+5)}-D_{j y}\right)$, where $D_{j(y+5)}$ refers to the density of species $j$ in the next FDP census. We also explored the role of basal area density of larger neighbors in preliminary analyses. Models including individual density had much greater support than models including basal area density $(\triangle \mathrm{AIC}>15$; Burnham and Anderson 2004) so the latter was not considered further. We also evaluated the performance of the variable-radius approach used to calculate fixed effects for larger neighbors. We compared models with fixed effects calculated for our variable radius with neighbors weighted equally and for a fixed $20 \mathrm{~m}$ radius with neighbors weighted equally, by their basal area, or by their basal area divided by their distance to the focal seedling. The fixed $20 \mathrm{~m}$ radius is the distance at which neighbor effects are no longer detected on BCI (Comita et al. 2010). Models with covariates calculated using our variable-radius approach had much greater support than models with covariates calculated using the other options ( $\triangle \mathrm{AIC} \geq 28)$.

We performed separate analyses for three relatedness indices. Webb et al. (2006) proposed and describe the first two indices, average relative phylodiversity (APd') and relative nearest taxon phylodiversity (NTPd'). Our third index consisted of five proportions corresponding to neighbor species that diverged from the focal species $<15$ Mya, 15-50 Mya, 50-80 Mya, 80-120 Mya, and $>120$ Mya. These ages correspond to the divergence time of major taxonomic ranks in the BCI flora (Kress at al. 2009, Magallón and Castillo 2009; D. L. Erickson et al., unpublished manuscript). Most congeners diverged 
$<15$ Mya. A few congeners and most families diverged between 15 and 50 Mya. The remaining families are represented by taxa that diverged 50-80 Mya. Major angiosperm clades diverged 80-120 Mya (e.g., asterids, rosids, commelinids). And, the oldest angiosperm lineages diverged $>120$ Mya (magnoliids, monocots, and eudicots). Because the proportion of neighbors in each category is a linear combination of the remaining categories, one arbitrarily chosen category ( $>120$ Mya) was initially excluded. Its effect was then evaluated by exchanging it with the first phylogenetic distance category deleted during the model fitting procedure and repeating the fitting procedure from the beginning. There was no difference between models including either of these two phylogenetic distance categories.

The model-fitting procedure began with all fixed effects and added random effects in a stepwise fashion (Bolker et al. 2009). Once the best random structure was found, we used stepwise deletion of fixed effects to test for the excluded divergence time category. We used conservative likelihood ratio tests to decide whether to retain each additional random effect (Bolker et al. 2009). We repeated this procedure for seedling neighbors only, for larger neighbors only, and for seedling and larger neighbors combined. We used the Akaike information criterion (AIC) to compare models for seedling neighbors only, larger neighbors only, and for both seedling and larger neighbors for each index of heterospecific divergence time. Finally, we also used AIC to compare the best models of all indices of heterospecific divergence time and select the most informative index.

The densities of seedling and larger heterospecific neighbors were log- and square root-transformed, respectively, to ensure linear relationships with the response variable, the log survival odds (Sheather 2009). Survival odds are defined as the ratio of the probability of survival to the probability of mortality. All variables were converted to standard normal deviates so that estimated fixed effects have comparable units (the effect of a one standard deviation increase in the fixed effect for the natural logarithm of the first-year survival odds).

\section{RESUlts}

We measured 19 traits for 170 to 354 species (Appendix: Table A1). Trait similarity increased with the level of relatedness for all traits in at least one habitat (i.e., sun or shade habitats, for leaves). Overall, 32 of 35 analyses were significant and 26 analyses were highly significant $(P<0.001)$. Trait conservatism is thus widespread in the BCI flora, indicating that closely related species are functionally similar.

The relevant 50-ha plot censuses (1995, 2000, 2005, and 2010) included 312874 individuals, which were identified to 318 species. The 17 annual seedling censuses included 62416 individuals. Thanks to the work of Garwood (2009), we identified 97.8\%, 98.5\%, and $98.6 \%$ of all seedlings to the species, genus, and family levels, respectively. Problematic genera included Cecropia, Miconia, and Piper, whose minute germinants cannot be identified to species. Otherwise, unidentified individuals had too little leaf tissue to identify. The 62416 seedlings included 417 species of all ages and 397 species of recruits.

Our analyses were restricted to 35719 focal recruits of 222 species. We excluded 13215 climbing seedlings because large climbers were not mapped in the FDP until 2007. We excluded 13482 free-standing seedlings because they were present in initial censuses, were not identified to species, or had undefined phylogenetic distance to heterospecific neighbors. Recruits with undefined phylogenetic distance to heterospecifics included (1) 104 seedlings without seedling neighbors, (2) 195 seedlings with neighborhoods composed only by conspecifics, and (3) 680 seedlings with unknown phylogenetic relationships for $>10 \%$ of their neighbors. The 26697 (=13215+13482) seedlings not used as focal recruits were included along with all focal recruits in calculations of seedling neighbor fixed effects. After one year, $46.5 \%$ of the 35719 focal recruits survived.

Models combining both neighbor size classes were clearly preferred over models including just one class. The loss of information when only one size class was used was crucial, especially for seedling neighbors (Table 2A). For the preferred models with both neighbor size classes, the model that treated phylogenetic neighborhood as the proportion of heterospecific neighbors grouped by divergence times had larger empirical support than models using APd' or NTPd' (Table 2B). The model using APd' was essentially unsupported ( $\Delta$ AIC > 12.89; Burnham and Anderson 2004).

Inclusion of random intercepts was strongly supported in every model, indicating that the mean probability of first-year seedling survival varied significantly among species, years, and sites. Interspecific variation in mean survival (intercepts) was the most important random effect (Appendix: Table A2). Coefficients associated with several fixed effects also varied significantly among species (Appendix: Table A2). Technically, species-level values of these coefficients are conditional modes of the random effects, which are the values of the random effects that maximize their conditional density given the data and the model parameters (Doran et al. 2007). We will use the shorthand "species-level effects" to refer to these conditional modes.

In the best model, seedling survival was significantly negatively related to conspecific density of both seedling and larger neighbors (Table 3). The species-level effects of conspecifics were negative for at least one neighbor size class for $>98 \%$ of species and for both neighbor size classes for $68 \%$ of species (Fig. 1A, B). Heterospecific density also had significant effects on seedling survival for both seedling and larger neighbors; however, the direction of the effect was positive for seedling neighbors and negative for larger neighbors (Table 3). The contrasting species-level effects of heterospecifics were 
TABLE 2. Models of first-year seedling survival compared (A) for neighborhoods comprised of seedling neighbors only, larger neighbors only, and both seedling and larger neighbors for three indices of heterospecific divergence time and (B) for the three indices of divergence time for models incorporating both seedling and larger neighbors.

\begin{tabular}{|c|c|c|c|c|c|}
\hline Model & Parameters $\dagger$ & AIC & $\Delta \mathrm{AIC}$ & AIC weight§ & $\begin{array}{c}\text { Evidence } \\
\text { ratio }\end{array}$ \\
\hline \multicolumn{6}{|c|}{$\begin{array}{l}\text { A) Comparison of models incorporating seedling } \\
\text { neighbors, larger neighbors, and both size classes }\end{array}$} \\
\hline \multicolumn{6}{|l|}{ 1) Divergence time intervals } \\
\hline All neighbors & 52 & 46058.23 & 0 & 1 & $>10^{16}$ \\
\hline Seedling neighbors & 25 & 46134.68 & 76.45 & 0 & $>10^{45}$ \\
\hline Larger neighbors & 20 & 46344.86 & 286.63 & 0 & \\
\hline \multicolumn{6}{|c|}{ 2) Relative nearest taxon phylodiversity (NTPd') } \\
\hline All neighbors & 38 & 46061.92 & 0 & 1 & $>10^{16}$ \\
\hline Seedling neighbors & 17 & 46136.67 & 74.75 & 0 & $>10^{45}$ \\
\hline \multirow{2}{*}{\multicolumn{6}{|c|}{ 3) Average relative phylodiversity (APd') }} \\
\hline & & & & & \\
\hline All neighbors & 31 & 46071.12 & 0 & 1 & $>10^{16}$ \\
\hline Seedling neighbors & 13 & 46145.26 & 74.14 & 0 & $>10^{43}$ \\
\hline Larger neighbors & 17 & 46346.89 & 275.77 & 0 & \\
\hline \multicolumn{6}{|c|}{$\begin{array}{l}\text { B) Comparison of three indices of heterospecific } \\
\text { divergence time for models with both size classes }\end{array}$} \\
\hline 1) Divergence time intervals & 52 & 46058.23 & 0 & 0.86 & 6.32 \\
\hline 2) NTPd' & 38 & 46061.92 & 3.69 & 0.14 & 99.75 \\
\hline 3) APd' & 31 & 46071.12 & 12.89 & 0.00 & \\
\hline
\end{tabular}

Notes: See Methods for descriptions of the divergence time indices. Models incorporate random effects for temporal, spatial, and interspecific variation. Fixed effects include conspecific and heterospecific neighbor density and one index of heterospecific divergence time.

$\uparrow$ The number of fixed effects, random effects, and correlations between species random effects estimated by the model.

$\ddagger$ Akaike information criterion.

$\S$ Probability that the given model is the best model relative to the whole set of candidate models.

- The number of times a given model is more likely than the next lower ranked model (Burnham and Anderson 2004).

consistent for $>91 \%$ of species (Fig. 1C, D). Finally, the proportion of closely related heterospecific neighbors (diverged $<15$ Mya from focal species) had significant positive effects for larger but not for seedling neighbors, although the parameter estimates for the latter were in the same direction (Table 3). Moreover, the species-level effects of growing among closely related heterospecifics were positive for at least one neighbor size class for $>75 \%$ of species and for both neighbor size classes for $53 \%$ of species (Fig. 1E, F). Thus, heterospecific

TABLE 3. Summary of fixed effects in the generalized linear mixed model that best explained firstyear seedling survival.

\begin{tabular}{|c|c|c|c|c|}
\hline Factor & Estimate & $\mathrm{SE}$ & $z$ & $P$ \\
\hline Intercept & -0.828 & 0.158 & -5.246 & $1.55 \times 10^{-07 * * *}$ \\
\hline \multicolumn{5}{|l|}{ Seedling neighbors } \\
\hline $\begin{array}{l}\text { Conspecific density } \\
\text { Heterospecific density } \\
\text { D }<15 \text { Mya } \\
\text { D } 15-50 \text { Mya } \\
\text { D } 50-85 \text { Mya } \\
\text { D } 85-120 \text { Mya }\end{array}$ & $\begin{array}{r}-0.826 \\
0.189 \\
0.033 \\
-0.008 \\
0.042 \\
-0.048\end{array}$ & $\begin{array}{l}0.183 \\
0.024 \\
0.023 \\
0.014 \\
0.026 \\
0.040\end{array}$ & $\begin{array}{r}-4.516 \\
7.968 \\
1.404 \\
-0.572 \\
1.637 \\
-1.213\end{array}$ & $\begin{array}{rl}6.29 & \times 10^{-06 * * *} \\
1.62 \times 10^{-15 * * *} & 0.160 \\
0.567 \\
0.102 \\
0.225\end{array}$ \\
\hline \multicolumn{5}{|l|}{ Neighbors $\geq 1 \mathrm{~cm} \mathrm{dbh}$} \\
\hline $\begin{array}{l}\text { Conspecific density } \\
\text { Heterospecific density } \\
\text { D }<15 \text { Mya } \\
\text { D } 15-50 \text { Mya } \\
\text { D } 50-85 \text { Mya } \\
\text { D } 85-120 \text { Mya }\end{array}$ & $\begin{array}{r}-0.106 \\
-0.095 \\
0.059 \\
0.017 \\
-0.015 \\
-0.006\end{array}$ & $\begin{array}{l}0.037 \\
0.025 \\
0.025 \\
0.014 \\
0.025 \\
0.034\end{array}$ & $\begin{array}{r}-2.865 \\
-3.780 \\
2.377 \\
1.174 \\
-0.611 \\
-0.168\end{array}$ & $\begin{array}{l}0.004^{* *} \\
<0.001^{* * *} \\
0.017 * \\
0.241 \\
0.541 \\
0.867\end{array}$ \\
\hline
\end{tabular}

Notes: D followed by a time interval refers to the proportion of heterospecifics that diverged from the focal seeding at the indicated interval in millions of years ago (Mya). Seedling neighbors are $<1 \mathrm{~cm}$ dbh and are in the same $1-\mathrm{m}^{2}$ plot with the focal seedling. Larger neighbors are $\geq 1 \mathrm{~cm}$ $\mathrm{dbh}$ and are within one crown radius of the seedling plot. With standardized variables, the intercept indicates the mean natural logarithm of the first-year survival odds when fixed effects are set to their average values. Fixed effects coefficients indicate the effect of a one standard deviation increase in the fixed effect for the natural logarithm of the first-year survival odds.

${ }^{*} P<0.05 ; * * P<0.01 ; * * * P<0.001$. 

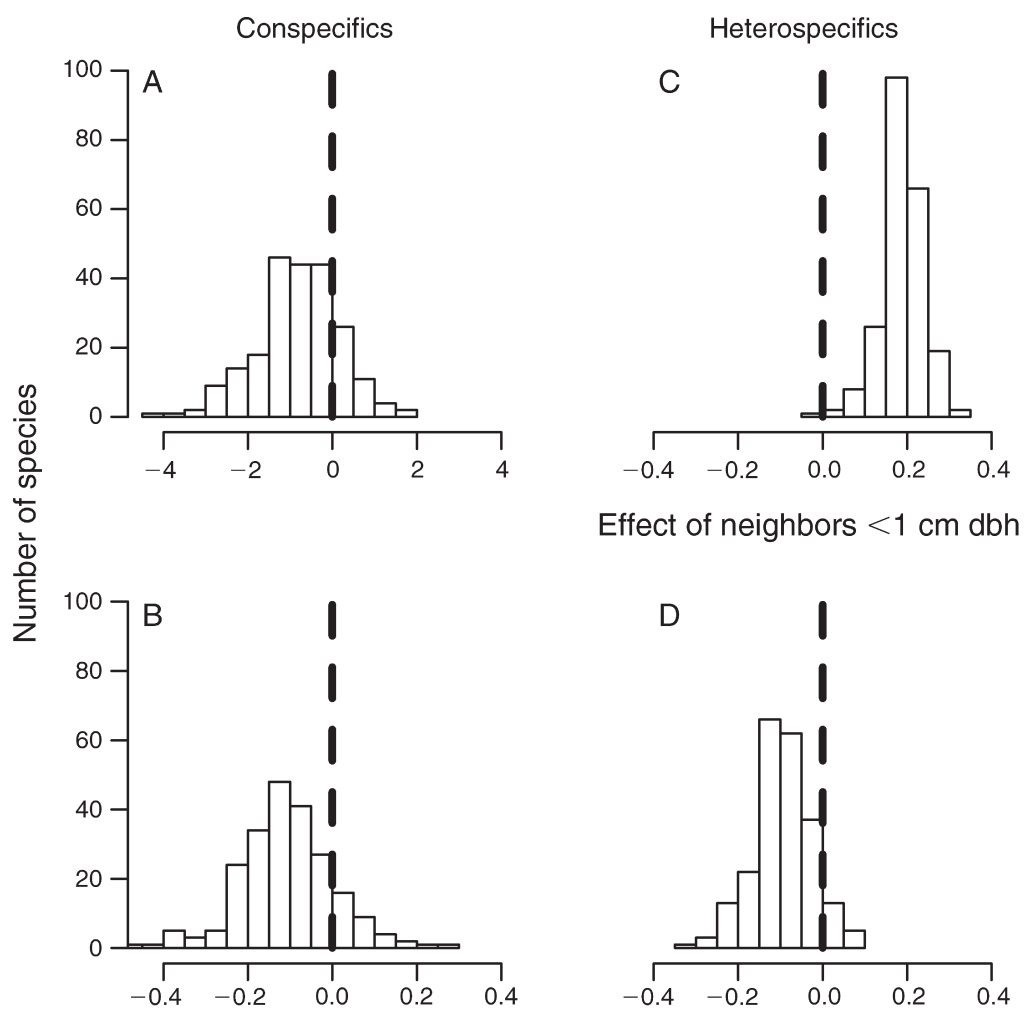

Closely related heterospecifics
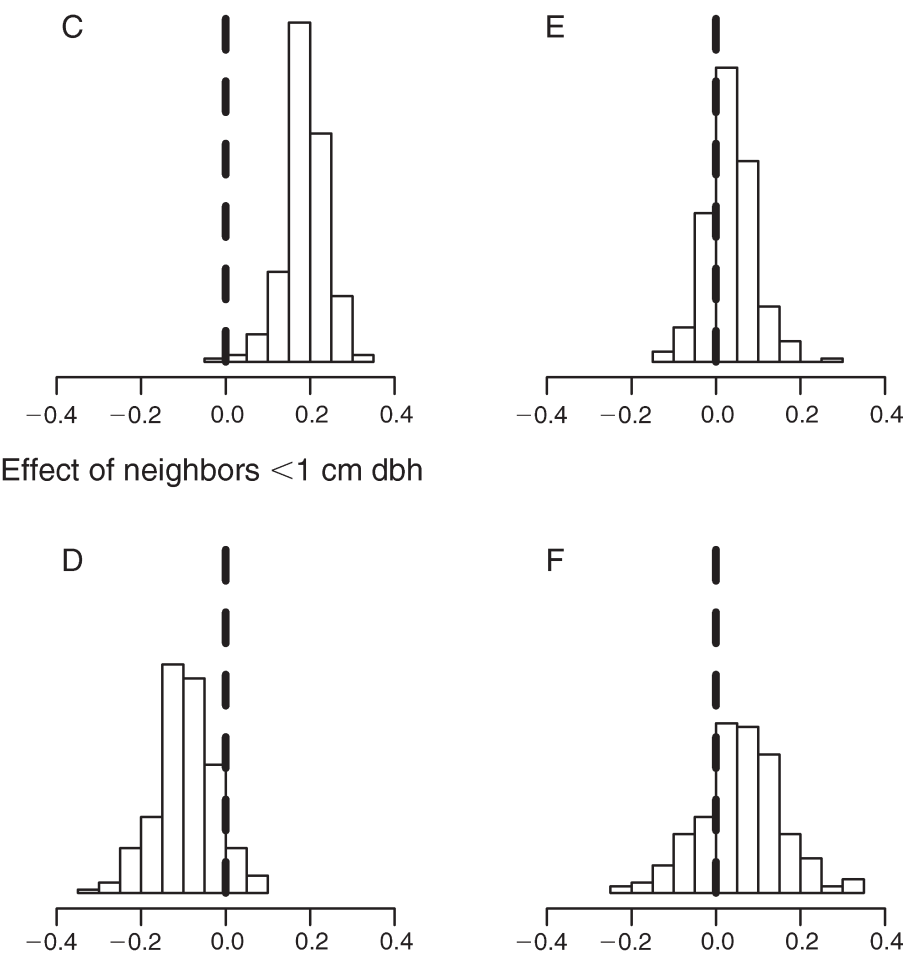

Effect of neighbors $\geq 1 \mathrm{~cm} \mathrm{dbh}$

FIG. 1. Histograms of species-level coefficients for relationships between first-year seedling survival and (A) conspecific density, (C) heterospecific density, and (E) heterospecific proportion closely related among seedling neighbors $(<1 \mathrm{~cm}$ diameter at breast height [dbh]) and (B) conspecific density, (D) heterospecific density, and (F) heterospecific proportion closely related among larger neighbors ( $\geq 1 \mathrm{~cm} \mathrm{dbh}$ ). Note the horizontal axis scale is identical in panels B through $\mathrm{F}$, but one order of magnitude larger in panel (A). Negative coefficients indicate survival decreases with an increase in the factor; positive coefficients indicate the opposite. The dashed vertical lines divide negative and positive coefficients. Closely related refers to neighbors that diverged from the focal species $<15$ million years ago (Mya). The effect of seedling neighbors in panel (E) was not significant, but is shown for comparison with larger neighbors. Coefficients combine fixed-effects estimates and the species-level random effect. See Methods for model-building details.

neighbor relatedness seems to have similar effects for both neighbor size classes.

We also treated divergence time to heterospecific neighbors as nearest taxon phylogenetic diversity (NTPd') and average neighbor phylogenetic diversity (APd'). APd' did not affect survival significantly (effect size $=0.004$ and $-0.007, z=0.17$ and $-0.33, P=0.87$ and 0.74 , for seedling and larger neighbors, respectively). NTPd' had a marginally significant negative effect for seedling neighbors and was insignificant for larger neighbors (effect size $=-0.046$ and $-0.014, z=-1.89$ and $-0.72, P=0.06$ and 0.47 , respectively). The negative effect for NTPd' and the positive effect for proportion closely related (Table 3) are consistent because larger values of NTPd' characterize communities whose nearest relatives are less closely related (Webb et al. 2006).

\section{Discussion}

We evaluated first-year seedling survival relative to the density, size, and species composition of neighbors in the moist tropical forests of BCI, Panama. Our focus on first-year seedlings minimizes ontogenetic variation in survival. First-year seedlings are also particularly vulnerable, thus, strong neighbor effects are expected. Our data included 35719 first-year seedlings of 222 species from 15 annual seedling cohorts, a highly resolved molecular phylogeny comprising $>98 \%$ of all species and individuals, and mapped locations and species-level identification of virtually all neighbors of all sizes. This enabled analyses that incorporated spatial, temporal, and interspecific variation, which has not been possible before. The link between phylogenetic relatedness and functional similarity was evaluated for 19 functional traits for 170 to 354 species. We evaluated the effects of seedling and larger neighbors, of conspecific and heterospecific neighbors, and of heterospecifics by evolutionary divergence times relative to focal seedlings. In the next section, we contrast the effects of conspecific vs. heterospecific neighbors and seedling vs. larger neighbors and conclude that host-specific pests shared among seedlings and shade cast by larger neighbors have 
TABLE 4. Tests of heterospecific density dependence of seedling survival in tropical and subtropical forests.

\begin{tabular}{|c|c|c|c|c|c|}
\hline Article & $\begin{array}{l}\text { Size of focal } \\
\text { seedling }\end{array}$ & $\begin{array}{l}\text { Level of } \\
\text { analysis }\end{array}$ & $\begin{array}{l}\text { Number of } \\
\text { analyses }\end{array}$ & $\begin{array}{l}\text { Neighborhood } \\
\text { radius }\end{array}$ & $\begin{array}{l}\text { Size of seedling } \\
\text { neighbors }\end{array}$ \\
\hline Anderson 2009 & emerged seedling & species & 2 & $35 \mathrm{~m}$ radius & $\leq 20 \mathrm{~cm}$ tall \\
\hline Comita et al. 2009 & $\begin{array}{l}>10 \mathrm{~cm} \text { tall, }<1 \\
\mathrm{~cm} \mathrm{dbh}\end{array}$ & species & 12 & $10 \mathrm{~m}$ radius & $>10 \mathrm{~cm}$ tall, $<1 \mathrm{~cm} \mathrm{dbh}$ \\
\hline $\begin{array}{l}\text { Comita and Hubbell } \\
2009\end{array}$ & $\begin{array}{l}>20 \mathrm{~cm} \text { tall, }<1 \\
\mathrm{~cm} \mathrm{dbh}\end{array}$ & species & 59 & $10 \mathrm{~m}$ radius & $>20 \mathrm{~cm}$ tall, $<1 \mathrm{~cm} \mathrm{dbh}$ \\
\hline Comita et al. 2010 & $\begin{array}{l}>20 \mathrm{~cm} \text { tall, }<1 \\
\mathrm{~cm} \mathrm{dbh}\end{array}$ & community & 1 & $30 \mathrm{~m}$ radius & $>20 \mathrm{~cm}$ tall, $<1 \mathrm{~cm} \mathrm{dbh}$ \\
\hline Chen et al. 2010 & $\leq 1 \mathrm{~cm} \mathrm{dbh}$ & community & 1 & $20 \mathrm{~m}$ radius & $\leq 1 \mathrm{~cm} \mathrm{dbh}$ \\
\hline $\begin{array}{l}\text { Kobe and Vriesendorp } \\
2011\end{array}$ & emerged seedling & species & 53 & $\begin{array}{l}\text { variable within } 20 \mathrm{~m} \\
\text { radius }\end{array}$ & emerged seedlings \\
\hline Lin et al. 2012 & $\leq 1 \mathrm{~cm} \mathrm{dbh}$ & community & 1 & $10 \mathrm{~m}$ radius & $\leq 1 \mathrm{~cm} \mathrm{dbh}$ \\
\hline Metz et al. 2010 & emerged seedling & community & 1 & $10 \mathrm{~m}$ radius & $\leq 1 \mathrm{~cm} \mathrm{dbh}$ \\
\hline $\begin{array}{l}\text { Queenborough et al. } \\
2007\end{array}$ & $\begin{array}{l}>1 \mathrm{~cm} \text { tall, }<1 \\
\quad \mathrm{~cm} \mathrm{dbh}\end{array}$ & community & 1 & $\begin{array}{l}1 \mathrm{~m} \text { wide anulus at } \\
3 \mathrm{~m} \text { radius from } \\
\text { focal seedling }\end{array}$ & $>1 \mathrm{~cm}$ tall, $<1 \mathrm{~cm} \mathrm{dbh}$ \\
\hline
\end{tabular}

Notes: Numbers in the last column tally the outcome of species- or community-level analyses of the effect of heterospecifics (density, basal area, or a neighborhood index considering abundance, size, and distance of heterospecific neighbors to the focal plants) on seedling survival. Reported studies included separate effects of conspecific and heterospecific seedlings and larger neighbors.

$\uparrow$ Not statistically significant $(P>0.05)$.

$\ddagger$ R. Kobe, personal communication.

$\S$ Four radii were tried $(5,10,15$, and $20 \mathrm{~m})$; results were insignificant for all of them.

๑ Nine radii from the focal seedling to the annulus' inner circle were tried $(0-8 \mathrm{~m})$; results were insignificant for all other radii.

strong negative effects on seedling survival. Yet survival improves if larger neighbors are close relatives.

\section{Conspecific density}

Conspecific negative density dependence (CNDD) is well established for tropical forest plants (reviewed by Wright 2002, Terborgh 2012). In our analyses, the negative effect of conspecific seedling density was more than four times stronger than the next most important effect (Table 3). Both intraspecific competition and movements of pests among neighbors could contribute to CNDD. Shared pests are implicated by a comparison of the strength of CNDD associated with seedling and larger neighbors.

Competition is size asymmetric among forest plants, with canopy trees and lianas intercepting light and maintaining extensive root systems that suppress shaded seedlings (Wright 2002, Coomes et al. 2011). As a consequence, seedling densities are often too low to involve direct seedling-seedling competition (Moles and Westoby 2004, Svenning et al. 2008). For these reasons, the strength of CNDD should increase with the size of conspecific neighbors if competition drives CNDD. In fact, CNDD associated with seedling neighbors was more than seven times stronger than CNDD associated with larger neighbors (see community-level coefficients in Table 3 and compare Fig. 1A and B, noting the order of magnitude difference in scales on the abscissa). Pests might cause strong CNDD among seedlings for at least two reasons. Many insect herbivores and leaf fungi are specialized to forest stratum as well as host species in Panama (Basset 2001, Gilbert et al. 2007); these enemies would contribute to CNDD among conspecific seedlings, but not among seedlings and larger conspecifics attacked by different stratum specialists. In addition, many soilborne pathogenic fungi are widespread and are not restricted to the adult neighborhood (Augspurger and Kelly 1984), yet cause CNDD because of differences in pathogenicity among host species (Augspurger and Wilkinson 2007, Hersh et al. 2012). Soil fungi pathogens may be likely responsible for CNDD among seedlings because seedlings are highly susceptible to fungal infection before cell wall thickening and lignification of tissues occur (Augspurger 1984, Neher et al. 1987, Bell et al. 2006, Mangan et al. 2010).We conclude that strong CNDD among seedlings is largely caused by movements of shared pests among neighboring hosts.

Chen et al. (2010) and Clark et al. (2012) also separated seedlings from larger neighbors and found stronger CNDD associated with seedlings. Janzen (1970) anticipated this result. Janzen (1970) distinguished enemies that respond to conspecific seedling density vs. the distance to large conspecifics and predicted that density-responsive enemies would cause greater host mortality than distance-responsive enemies because density-responsive enemies persist until host densities are unprofitably low and track their hosts over larger areas than do distance-responsive enemies. This dichotomy between density- and distance-responsive enemies is reinforced when enemies are also specialized to forest strata so that enemies specialized on canopy adults do not attack understory seedlings (Basset 2001, Gilbert et al. 2007). CNDD mediated by pests might be particularly strong among seedlings for these reasons.

\section{Heterospecific density}

A positive effect of heterospecific seedlings and a negative effect of larger heterospecifics were the second 
TABLE 4. Extended.

\begin{tabular}{|c|c|c|c|c|c|c|}
\hline \multicolumn{3}{|c|}{ Effect of seedling neighbors } & \multirow{2}{*}{$\begin{array}{c}\text { Size of large } \\
\text { neighbors }\end{array}$} & \multicolumn{3}{|c|}{ Effect of large neighbors } \\
\hline- & ns† & + & & - & $\mathrm{ns} \dagger$ & + \\
\hline 0 & 1 & 1 & $>5 \mathrm{~m}$ tall & 0 & 2 & 0 \\
\hline 0 & 10 & 2 & $>1 \mathrm{~cm} \mathrm{dbh}$ & 0 & 10 & 2 \\
\hline 0 & 51 & 8 & $>1 \mathrm{~cm} \mathrm{dbh}$ & 0 & 55 & 4 \\
\hline 0 & 1 & 0 & $>1 \mathrm{~cm} \mathrm{dbh}$ & 0 & 0 & 1 \\
\hline 0 & 0 & 1 & $>1 \mathrm{~cm} \mathrm{dbh}$ & 0 & 1 & 0 \\
\hline $4 \%$ & $41+$ & $8 末$ & $>5 \mathrm{~cm} \mathrm{dbh}$ & 2 & 49 & 2 \\
\hline 0 & 0 & 1 & $>1 \mathrm{~cm} \mathrm{dbh}$ & 0 & 1 & 0 \\
\hline 0 & 1 & 0 & $>10 \mathrm{~cm} \mathrm{dbh}$ & 0 & 1 & 0 \\
\hline 0 & 1 & 0 & $>10 \mathrm{~cm} \mathrm{dbh}$ & 1 & 0 & 0 \\
\hline
\end{tabular}

and fourth strongest effects, respectively (Table 3, Fig. 1C, D). Also, effect sizes were remarkably similar for large conspecific and heterospecific neighbors (Table 3, Fig. 1B, D). Collectively, this pattern of effect sizes is consistent with shared seedling responses to variation in light availability. We measured global radiation $1 \mathrm{~m}$ above the ground at all seedling plots for one week during 2012 with Apogee SP-110 pyranometers (Apogee Instruments, Logan, USA). Global radiation was negatively correlated with the density of large heterospecifics estimated from the 2010 FDP census $(r=-0.23$, $P<0.001)$. Thus, the negative effects of large neighbors are consistent with light limitation of seedling survival (Kobe and Vriesendorp 2011), although large neighbors also likely contribute to soil resource limitation.

Variation in understory light might also contribute to the positive association between heterospecific seedling density and focal seedling survival (Fig. 1C). Where there are fewer large, overtopping neighbors, greater understory light levels promote both seedling recruitment as well as seedling survival (e.g., Rüger et al. 2009). As a consequence, seedling survival and heterospecific seedling abundance will tend to covary with understory light levels. A second mechanism might reinforce positive heterospecific effects in the seedling layer. High heterospecific density might limit encounters between hosts and their host-specific enemies and thereby increase host survival in a "herd effect" (Wills 1996). Nine recent studies have evaluated relationships between seedling survival and the density of heterospecific seedlings and larger neighbors in tropical and subtropical forests (Table 4). Six report significant positive relationships, as found here (Fig. 1C). We suspect these positive associations are largely due to covariation of seedling survival, heterospecific seedling density, and understory light levels, but we cannot discount the "herd effect."

Surprisingly, the negative effect of the density of large heterospecific neighbors on seedling survival (Fig. 1D) has rarely been found in the literature. In fact, just three of 131 published analyses for tropical and subtropical forests found the significant negative relationship that we found (Table 4; tally of effects of large heterospecific neighbors, i.e., $>5 \mathrm{~m}$ tall or $1 \mathrm{~cm} \mathrm{dbh).} \mathrm{Methodological}$ differences might explain the strong contrast with our results. Our large heterospecific neighbors were located within one crown radius and potentially overtop focal seedlings. In contrast, all other studies use fixed-radius plots, which might exclude large individuals with spreading crowns that overtop focal seedlings and/or include small individuals that do not. For these reasons, variable-radius plots adjusted to the size of the plants under consideration might be an improvement over fixed-radius plots (see Kobe and Vriesendorp 2011). The density of large heterospecific neighbors might have larger effects on seedling survival than is currently appreciated.

\section{Phylogenetic relatedness of heterospecifics}

We examined three metrics to represent relatedness of heterospecific neighbors. Two, relative nearest taxon phylodiversity (NTPd') and proportions of heterospecific neighbors grouped by divergence times, are sensitive to the presence of closely related neighbors and gave similar results (Table 2B). In both analyses, focal seedling survival tended to increase in the presence of closely related neighbors (see Results; Fig. 1E, F). In contrast, average relative phylodiversity (APd') obscures effects associated with closely related neighbors and was not supported (Table 2B). NTPd' discards information concerning all but the most closely related neighbor. In contrast, proportions of heterospecifics grouped by divergence times further indicates that more distantly related neighbors did not affect survival significantly (Table 3). Separating heterospecific neighbors by divergence times has the potential to provide additional insight not possible with metrics based on mean or minimum divergence times.

The consistent positive effects of the most closely related heterospecific neighbors on seedling survival (Fig. $1 \mathrm{E}, \mathrm{F})$ contrast strongly with the consistent negative 
TABLE 5. Tests of the hypothesis that plant performance varies with the phylogenetic relatedness of neighboring plants.

\begin{tabular}{|c|c|c|c|c|c|}
\hline Article & Biome & Life-form & $\begin{array}{l}\text { Spatial } \\
\text { scale }\end{array}$ & $\begin{array}{c}\text { Life stage } \\
\text { of focal plant }\end{array}$ & $\begin{array}{l}\text { Neighbor } \\
\text { data }\end{array}$ \\
\hline \multicolumn{6}{|c|}{$\begin{array}{l}\text { A) Analyses based on the } \\
\text { Angiosperm Phylogeny Group } \\
\text { working hypothesis }\end{array}$} \\
\hline Castillo et al. 2010 & arid & shrub and cacti & patch & seedling & presense/abser \\
\hline
\end{tabular}

Webb et al. 2006

Bagchi et al. 2010

Metz et al. 2010

Liu et al. 2012

B) Analyses based on bar code phylogenies

Uriarte et al. 2010

Burns and Strauss 2011

This study

$\begin{array}{ll}\text { tropical forest } & \text { trees } \\ \text { tropical forest } & \text { trees } \\ \text { tropical forest } & \text { trees }\end{array}$

subtropical forest

trees

trees

marsh grassland

grasses and forbs "site"

crown radius

tropical forest

trees seedling

seedling

seedling

seedling
$>1 \mathrm{~cm} \mathrm{dbh}$ seedling

seedling presense/absence

presense/absence

abundance

presense/absence

presense/absence presense/absence

abundance

Notes: Numbers in the last column tally the outcome of species-level tests (Castillo et al. 2010, one species; Uriarte et al. 2010,19 species) or community-level tests of the hypothesis. Neighborhood variables include divergence time to the largest or the dominant neighbor (DT), average divergence time (ADT), minimum divergence time (min(DT)), average relative phylodiversity (APd'), relative nearest taxon phylodiversity (NTPd'), and net relatedness index (NRI). Webb et al. (2002, 2006) define APd', NTPd', and NRI.

$\dagger$ Not statistically significant $(P>0.05)$.

effects of conspecific neighbors (Fig. 1A, B) and the absence of significant effects of more distantly related neighbors (Table 3). Several factors might contribute. As shown by significant phylogenetic conservatism in 19 functional traits, closely related species tend to be functionally similar (Appendix: Table A1). Accordingly, closely related species tend to share mutualists and habitat affinities, which would favor positive associations, and also pests and limiting resources, which would favor negative associations (Herre et al. 2005, Burns and Strauss 2011, Baraloto et al. 2012, Gilbert et al. 2012). The balance between factors favoring positive and negative associations apparently changes dramatically between conspecifics and the most closely related heterospecifics, and then again between the most closely and more distantly related heterospecifics. We speculate that two mechanisms might explain this. Earlier we argued that pests are the principal cause of strong CNDD in the seedling layer (see Discussion: Conspecific density). We speculate that pests responsible for seedling mortality tend to be narrow host specialists or to have much reduced impact on alternative hosts (see Hersh et al. 2012). This first mechanism could explain the absence of negative effects of heterospecific neighbors, but cannot explain positive effects limited to the most closely related heterospecifics. A second mechanism is necessary. On BCI, habitat affinities defined by microtopography and soil fertility tend to be similar among the most closely related tree species (congeners), but not among slightly more distantly related species (confamilials; Baldeck et al. 2013). Together, reduced impact of pests on alternative hosts and shared habitat affinities restricted to the most closely related species could explain CNDD, positive effects of the most closely related heterospecific neighbors, and the lack of any effect of more distantly related neighbors.

We are aware of 10 studies (including this one) that evaluated the performance of individual plants relative to the evolutionary divergence times of their neighbors. No two studies used the same methods. Three incorporated conspecific and heterospecific neighbors into a single independent variable (Uriarte et al. 2004, 2010, Paine et 
TABLE 5. Extended.

\begin{tabular}{|c|c|c|c|c|c|}
\hline \multirow{2}{*}{$\begin{array}{l}\text { Response } \\
\text { variable }\end{array}$} & \multirow{2}{*}{$\begin{array}{l}\text { Neighbor } \\
\text { variables }\end{array}$} & \multirow{2}{*}{$\begin{array}{l}\text { Life stage } \\
\text { of neighbor }\end{array}$} & \multicolumn{3}{|c|}{$\begin{array}{l}\text { Performance improves where } \\
\text { neighbors are closely related }\end{array}$} \\
\hline & & & - & nst & + \\
\hline survival 1 & DT & largest & 0 & 1 & 0 \\
\hline survival 1 & $\min (\mathrm{DT})$ & all & 0 & 1 & 0 \\
\hline survival 1 & ADT & all & 0 & 1 & 0 \\
\hline growth & DT & largest & 0 & 1 & 0 \\
\hline growth & $\min (\mathrm{DT})$ & all & 1 & 0 & 0 \\
\hline growth & ADT & all & 0 & 1 & 0 \\
\hline establishment & DT & largest & 1 & 0 & 0 \\
\hline establishment & $\min (\mathrm{DT})$ & all & 0 & 1 & 0 \\
\hline establishment & ADT & all & 0 & 1 & 0 \\
\hline survival 2 & DT & largest & 0 & 1 & 0 \\
\hline survival 2 & $\min (\mathrm{DT})$ & all & 0 & 0 & 1 \\
\hline survival 2 & ADT & all & 1 & 0 & 0 \\
\hline \multirow[t]{2}{*}{ survival } & APd' & seedling & 0 & 1 & 0 \\
\hline & NTPd' & seedling & 0 & 1 & 0 \\
\hline survival & DT & nearby adult & 1 & 0 & 0 \\
\hline growth & DT & nearby adult & 0 & 1 & 0 \\
\hline \multirow[t]{2}{*}{ survival $0-1 \mathrm{yr}$} & APd' & seedling & 0 & 1 & 0 \\
\hline & APd' & $>1 \mathrm{~cm} \mathrm{dbh}$ & 1 & 0 & 0 \\
\hline \multirow[t]{2}{*}{ survival $1-2 \mathrm{yr}$} & APd' & seedling & 1 & 0 & 0 \\
\hline & APd' & $>1 \mathrm{~cm} \mathrm{dbh}$ & 0 & 0 & 1 \\
\hline \multirow{2}{*}{ survival } & APd' & $\geq 1 \mathrm{~cm} \mathrm{dbh}$ & 1 & 0 & 0 \\
\hline & NTPd' & $\geq 1 \mathrm{~cm} \mathrm{dbh}$ & 1 & 0 & 0 \\
\hline survival & NRI: live vs. dead trees & $>1 \mathrm{~cm} \mathrm{dbh}$ & 2 & 3 & 14 \\
\hline germination & DT & dominant & 0 & 0 & 1 \\
\hline growth & DT & dominant & 1 & 0 & 0 \\
\hline survival & DT & dominant & 0 & 0 & 1 \\
\hline \multirow[t]{2}{*}{ survival } & percentage $<15$ Mya & seedling & 0 & 1 & 0 \\
\hline & percentage $<15$ Mya & $>1 \mathrm{~cm} \mathrm{dbh}$ & 0 & 0 & 1 \\
\hline
\end{tabular}

al. 2012). This approach precludes separating the effects of conspecifics and heterospecifics, and, for this reason, these analyses are not considered further. Uriarte et al. (2010) performed a second analysis of mortality that excluded conspecific neighbors and is included.

The eight remaining studies conducted 46 analyses (Table 5). Nineteen detected significant increases in performance among closely related neighbors, 11 detected the opposite, and 16 were insignificant (Table 5A and B). This tally may still be misleading because taxonomic resolution explains substantial variation in the results. Taxonomic resolution was provided by the Angiosperm Phylogeny Group (APG) hypothesis (Webb et al. 2006, Bagchi et al. 2010, Castillo et al. 2010, Metz et al. 2010, Liu et al. 2012) or, as we found, by nearly fully resolved bar code phylogenies (Uriarte et al. 2010, Burns and Strauss 2011). Significant improvements in performance among closely related neighbors were detected in 17 of 24 analyses based on bar code phylogenies, but in just 2 of 22 analyses based on the APG hypothesis (Table 5). The difference is highly significant (Fisher exact test, $P=$ 0.000022). This suggests the taxonomic resolution of the APG hypothesis might mask effects associated with the most closely related heterospecifics. This is not surprising because the APG hypothesis currently lacks the resolution necessary to distinguish the most closely related heterospecifics. In our analyses, survival only improved in the presence of the most closely related heterospecifics, whose divergence times $(<15$ Mya) are below the temporal resolution of the APG hypothesis. Improved performance for plants growing among closely related heterospecifics might be more widespread than is currently appreciated.

\section{Conclusions}

On BCI, first-year seedling survival is (1) strongly negatively related to conspecific seedling density, (2) negatively related to the densities of larger conspecifics and heterospecifics, (3) positively related to heterospecific seedling density, and (4) positively related to the proportion of closely related heterospecific neighbors (Fig. 1, Table 3). Our interpretation follows. First, conspecific seedlings share pests, which reduce survival as conspecific seedling density increases. We discount direct competition because seedling neighbors rarely contact one another and their impacts on resource use are likely slight. Second, larger neighbors cause similar reductions in light availability and possibly soil resource availability regardless of species. We discount pest-mediated effects between seedlings and large conspecific neighbors because effect sizes associated with large conspecifics 
and heterospecifics were very similar (Fig. 1B, D, Table 3 ); many insect herbivores and leaf fungi are known to be stratum specialists in central Panama (Basset et al. 2003, Gilbert et al. 2007), and soil-borne pathogens are widely distributed across the forest soil (Augspurger and Kelly 1984). Third, spatial variation in understory light availability links survival and heterospecific seedling density, with facilitation perhaps playing a role. And fourth, the presence of large closely related neighbors is associated with appropriate microhabitats that favor seedling survival (cf. Kraft and Ackerly 2010, Baraloto et al. 2012). Finally, we found no support for the principal prediction of pest dilution hypotheses: Neighborhoods composed of distantly related species did not favor survival, but rather proximity to very closely related heterospecifics favored survival.

We used an unprecedented data set and two analytical innovations to document complex and unexpected interactions among plants in tropical forests. The data set includes $>62000$ seedlings from 15 annual cohorts, the mapped locations of 380000 larger plants, species-level identification of 465 species, and a bar code phylogeny that resolved divergence times for all but $4 \%$ of the species pairs. Analytical innovations include variable-radius plots adjusted to the size of each neighbor and a partition of the relatedness of neighbors by divergence times. Unexpected results include sevenfold stronger negative conspecific interactions among seedlings than between seedlings and large conspecifics, strong negative effects of large heterospecific neighbors, and significant positive effects of closely related heterospecific neighbors.

\section{ACKNOWLEDGMENTS}

E. Lebrija-Trejos was supported by a post-doctoral fellowship from the Smithsonian Institution Global Earth Observatory and the Institute of the Environment, University of Minnesota. Analyses were facilitated by workshops sponsored by NSF grant DEB-1046113 to S. Davies.

\section{Literature Cited}

Alvarez-Loayza, P., and J. Terborgh. 2011. Fates of seedling carpets in an Amazonian floodplain forest: intra-cohort competition or attack by enemies? Journal of Ecology 99: $1045-1054$.

Anderson, J. T. 2009. Positive density dependence in seedlings of the neotropical tree species Garcinia macrophylla and Xylopia micans. Journal of Vegetation Science 20:27-36.

Arnold, A. E., Z. Maynard, G. S. Gilbert, P. D. Coley, and T. A. Kursar. 2000. Are tropical fungal endophytes hyperdiverse? Ecology Letters 3:267-274.

Augspurger, C. K. 1984. Seedling survival of tropical tree species: interactions of dispersal distance, light-gaps, and pathogens. Ecology 65:1705-1712.

Augspurger, C. K., and C. K. Kelly. 1984. Pathogen mortality of tropical tree seedlings: experimental studies of the effects of dispersal distance, seedling density, and light conditions. Oecologia 61:211-217.

Augspurger, C. K., and H. T. Wilkinson. 2007. Host specificity of pathogenic Pythium species: implications for tree species diversity. Biotropica 39:702-708.

Bagchi, R., M. C. Press, and J. D. Scholes. 2010. Evolutionary history and distance dependence control survival of dipterocarp seedlings. Ecology Letters 13:51-59.
Baldeck, C. A., et al. 2013. A taxonomic comparison of local habitat niches of tropical trees. Oecologia 173:1491-1498.

Baraloto, C., et al. 2012. Using functional traits and phylogenetic trees to examine the assembly of tropical tree communities. Journal of Ecology 100:690-701.

Basset, Y. 2001. Communities of insect herbivores foraging on saplings versus mature trees of Pourouma bicolor (Cecropiaceae) in Panama. Oecologia 129:253-260.

Basset, Y., et al. 2012. Arthropod diversity in a tropical forest. Science 338:1481-1484.

Basset, Y., P. M. Hammond, H. Barrios, J. D. Holloway, and S. E. Miller. 2003. Vertical stratification of arthropod assemblages. Pages 17-27 in Y. Basset, V. Novotny, S. E. Miller, and R. L. Kitching, editors. Arthropods of tropical forests: spatio-temporal dynamics and resource use in the canopy. Cambridge University Press, Cambridge, UK.

Bell, T., R. P. Freckleton, and O. T. Lewis. 2006. Plant pathogens drive density-dependent seedling mortality in a tropical tree. Ecology Letters 9:569-574.

Bolker, B. M., M. E. Brooks, C. J. Clark, S. W. Geange, J. R. Poulsen, M. H. H. Stevens, and J.-S. S. White. 2009. Generalized linear mixed models: a practical guide for ecology and evolution. Trends in Ecology and Evolution 24:127-135.

Britton, T., C. L. Anderson, D. Jacquet, S. Lundqvist, and K. Bremer. 2007. Estimating divergence times in large phylogenetic trees. Systematic Biology 56:741-752.

Burnham, K. P., and D. R. Anderson. 2004. Multimodel inference: understanding AIC and BIC in model selection. Sociological Methods and Research 33:261-304.

Burns, J. H., and S. Y. Strauss. 2011. More closely related species are more ecologically similar in an experimental test. Proceedings of the National Academy of Sciences USA 108: 5302-5307.

Castillo, J. P., M. Verdú, and A. Valiente-Banuet. 2010. Neighborhood phylodiversity affects plant performance. Ecology 91:3656-3663.

Chen, L., X. Mi, L. S. Comita, L. Zhang, H. Ren, and K. Ma. 2010. Community-level consequences of density dependence and habitat association in a subtropical broad-leaved forest. Ecology Letters 13:695-704.

Chesson, P. 2000. Mechanisms of maintenance of species diversity. Annual Review of Ecology and Systematics 31: 343-366.

Clark, C. J., J. R. Poulsen, and D. J. Levey. 2012. Vertebrate herbivory impacts seedling recruitment more than niche partitioning or density-dependent mortality. Ecology 93:554564.

Comita, L. S., and S. P. Hubbell. 2009. Local neighborhood and species' shade tolerance influence survival in a diverse seedling bank. Ecology 90:328-334.

Comita, L. S., H. C. Muller-Landau, S. Aguilar, and S. P. Hubbell. 2010. Asymmetric density dependence shapes species abundances in a tropical tree community. Science 329:330-332.

Comita, L. S., M. Uriarte, J. Thompson, I. Jonckheere, C. D. Canham, and J. K. Zimmerman. 2009. Abiotic and biotic drivers of seedling survival in a hurricane-impacted tropical forest. Journal of Ecology 97:1346-1359.

Condit, R. 1998. Tropical forest census plots: methods and results from Barro Colorado Island, Panama and a comparison with other plots. Springer-Verlag, Berlin, Germany.

Coomes, D. A., E. R. Lines, and R. B. Allen. 2011. Moving on from Metabolic Scaling Theory: hierarchical models of tree growth and asymmetric competition for light. Journal of Ecology 99:748-756.

Doran, H., D. Bates, P. Bliese, and M. Dowling. 2007. Estimating the multilevel Rasch model: with the lme4 package. Journal of Statistical Software 20:1-18. 
Garwood, N. C. 1983. Seed germination in a seasonal tropical forest in Panama: a community study. Ecological Monographs 53:159-181.

Garwood, N. C. 2009. Seedlings of Barro Colorado Island and the Neotropics. Cornell University Press, Ithaca, New York, USA.

Gilbert, G. S., R. Magarey, K. Suiter, and C. O. Webb. 2012. Evolutionary tools for phytosanitary risk analysis: phylogenetic signal as a predictor of host range of plant pests and pathogens. Evolutionary Applications 5:869-878.

Gilbert, G. S., D. R. Reynolds, and A. Bethancourt. 2007. The patchiness of epifoliar fungi in tropical forests: host range, host abundance, and environment. Ecology 88:575-581.

Herre, E., D. Kyllo, S. Mangan, R. Husband, L. Mejia, and A.-H. Eom. 2005. An overview of arbuscular mycorrhizal fungal composition, distribution and host effects from a tropical moist forest. Pages 204-225 in D. F. R. P. Burslem, M. A. Pinard, and S. E. Hartley, editors. Biotic interactions in the tropics: their role in the maintenance of species diversity. Cambridge University Press, Cambridge, UK.

Hersh, M. H., R. Vilgalys, and J. S. Clark. 2012. Evaluating the impacts of multiple generalist fungal pathogens on temperate tree seedling survival. Ecology 93:511-520.

Janzen, D. H. 1970. Herbivores and the number of tree species in tropical forests. American Naturalist 104:501-528.

Kembel, S. W., P. D. Cowan, M. R. Helmus, W. K. Cornwell, H. Morlon, D. D. Ackerly, S. P. Blomberg, and C. O. Webb. 2010. Picante: $\{R\}$ tools for integrating phylogenies and ecology. Bioinformatics 26:1463-1464.

Kobe, R. K., and C. F. Vriesendorp. 2011. Conspecific density dependence in seedlings varies with species shade tolerance in a wet tropical forest. Ecology Letters 14:503-510.

Kraft, N. J. B., and D. D. Ackerly. 2010. Functional trait and phylogenetic tests of community assembly across spatial scales in an Amazonian forest. Ecological Monographs 80: 401-422.

Kress, W. J., D. L. Erickson, F. A. Jones, N. G. Swenson, R. Perez, O. Sanjur, and E. Bermingham. 2009. Plant DNA barcodes and a community phylogeny of a tropical forest dynamics plot in Panama. Proceedings of the National Academy of Sciences USA 106:18621-18626.

Lin, L., L. S. Comita, Z. Zheng, and M. Cao. 2012. Seasonal differentiation in density-dependent seedling survival in a tropical rain forest. Journal of Ecology 100:905-914.

Liu, X., M. Liang, R. S. Etienne, Y. Wang, C. Staehelin, and S. Yu. 2012. Experimental evidence for a phylogenetic JanzenConnell effect in a subtropical forest. Ecology Letters 15: $111-118$.

Magallón, S., and A. Castillo. 2009. Angiosperm diversification through time. American Journal of Botany 96:349-365.

Mangan, S. A., S. A. Schnitzer, E. A. Herre, K. M. L. Mack, M. C. Valencia, E. I. Sanchez, and J. D. Bever. 2010. Negative plant-soil feedback predicts tree-species relative abundance in a tropical forest. Nature 466:752-755.

Metz, M. R., W. P. Sousa, and R. Valencia. 2010. Widespread density-dependent seedling mortality promotes species coexistence in a highly diverse Amazonian rain forest. Ecology 91: 3675-3685.

Moles, A. T., and M. Westoby. 2004. What do seedlings die from and what are the implications for evolution of seed size? Oikos 106:193-199.

Muller-Landau, H. C., et al. 2006. Testing metabolic ecology theory for allometric scaling of tree size, growth and mortality in tropical forests. Ecology Letters 9:575-588.
Neher, D. A., C. K. Augspurger, and H. T. Wilkinson. 1987. Influence of age structure of plant populations on dampingoff epidemics. Oecologia 74:419-424.

Paine, C. E. T., N. Norden, J. Chave, P.-M. Forget, C. Fortunel, K. G. Dexter, and C. Baraloto. 2012. Phylogenetic density dependence and environmental filtering predict seedling mortality in a tropical forest. Ecology Letters 15: $34-41$.

Puerta-Piñero, C., H. C. Muller-Landau, O. Calderón, and S. J. Wright. 2013. Seed arrival in tropical forest tree fall gaps. Ecology 94:1552-1562.

Queenborough, S. A., D. F. R. P. Burslem, N. C. Garwood, and R. Valencia. 2007. Neighborhood and community interactions determine the spatial pattern of tropical tree seedling survival. Ecology 88:2248-2258.

R Development Core Team. 2012. R: a language and environment for statistical computing. R Foundation for Statistical Computing, Vienna, Austria.

Rüger, N., A. Huth, S. P. Hubbell, and R. Condit. 2009. Response of recruitment to light availability across a tropical lowland rain forest community. Journal of Ecology 97:1360 1368.

Sheather, S. 2009. A modern approach to regression with R. Springer, New York, New York, USA.

Svenning, J., T. Fabbro, and S. J. Wright. 2008. Seedling interactions in a tropical forest in Panama. Oecologia 155: $143-150$.

Terborgh, J. 2012. Enemies maintain hyperdiverse tropical forests. American Naturalist 179:303-314.

Uriarte, M., R. Condit, C. D. Canham, and S. P. Hubbell. 2004. A spatially explicit model of sapling growth in a tropical forest: does the identity of neighbours matter? Journal of Ecology 92:348-360.

Uriarte, M., N. G. Swenson, R. L. Chazdon, L. S. Comita, W. John Kress, D. Erickson, J. Forero-Montaña, J. K. Zimmerman, and J. Thompson. 2010. Trait similarity, shared ancestry and the structure of neighbourhood interactions in a subtropical wet forest: implications for community assembly. Ecology Letters 13:1503-1514.

Vamosi, S. M., S. B. Heard, J. C. Vamosi, and C. O. Webb. 2009. Emerging patterns in the comparative analysis of phylogenetic community structure. Molecular Ecology 18: $572-592$.

Webb, C. O., D. D. Ackerly, M. A. McPeek, and M. J. Donoghue. 2002. Phylogenies and community ecology. Annual Review of Ecology, Evolution, and Systematics 33: 475-505.

Webb, C. O., and M. J. Donoghue. 2005. Phylomatic: tree assembly for applied phylogenetics. Molecular Ecology Notes 5:181-183.

Webb, C. O., G. S. Gilbert, and M. J. Donoghue. 2006. Phylodiversity-dependent seedling mortality, size structure, and disease in a Bornean rain forest. Ecology 87:123-131.

Wills, C. 1996. Safety in diversity. New Scientist 38-42.

Wilson, J. B., R. K. Peet, J. Dengler, and M. Pärtel. 2012. Plant species richness: the world records. Journal of Vegetation Science 23:796-802.

Wright, S. J. 2002. Plant diversity in tropical forests: a review of mechanisms of species coexistence. Oecologia 130:1-14.

Wright, S. J., O. Calderón, A. Hernandéz, and H. C. MullerLandau. 2005. Annual and spatial variation in seedfall and seedling recruitment in a neotropical forest. Ecology 86:848860 .

Wright, S. J., et al. 2010. Functional traits and the growthmortality trade-off in tropical trees. Ecology 91:3664-3674.

\section{Supplemental Material}

\section{Appendix}

Tests of phylogenetic signal in functional traits and summary of model-fitting procedure (Ecological Archives E095-079-A1). 